\title{
Characterizations of InN Thin Films Grown on Si (110) Substrate by Reactive Sputtering
}

\author{
M. Amirhoseiny, Z. Hassan, S. S. Ng, and M. A. Ahmad \\ Nano-Optoelectronics Research and Technology Laboratory, School of Physics, Universiti Sains Malaysia, 11800 Penang, Malaysia \\ Correspondence should be addressed to M. Amirhoseiny, maa10_phy070@student.usm.my
}

Received 19 February 2011; Revised 18 April 2011; Accepted 21 May 2011

Academic Editor: Gong Ru Lin

Copyright ( $) 2011 \mathrm{M}$. Amirhoseiny et al. This is an open access article distributed under the Creative Commons Attribution License, which permits unrestricted use, distribution, and reproduction in any medium, provided the original work is properly cited.

Indium nitride ( $\mathrm{InN}$ ) thin films were deposited onto $\mathrm{Si}(110)$ by reactive sputtering and pure In target at ambient temperature. The effects of the Ar- $\mathrm{N}_{2}$ sputtering gas mixture on the structural properties of the films were investigated by using scanning electron microscope, energy-dispersive X-ray spectroscopy, atomic force microscopy, and X-ray diffraction techniques. The optical properties of InN layers were examined by micro-Raman and Fourier transform infrared (FTIR) reflectance spectroscopy at room temperature. Structural analysis specified nanocrystalline structure with crystal size of $15.87 \mathrm{~nm}, 16.65 \mathrm{~nm}$, and $41.64 \mathrm{~nm}$ for InN films grown at $\mathrm{N}_{2} / \mathrm{Ar}$ ratio of $100 / 0,75 / 25$, and 50/50, respectively. The Raman spectra indicates well defined peaks at 578, 583, and $583 \mathrm{~cm}^{-1}$, which correspond to the $A_{1}$ (LO) phonon of the hexagonal InN films grown at gas ratios of $100: 0,75: 25$ and $50: 50$ $\mathrm{N}_{2}$ : Ar, respectively. Results of FTIR spectroscopy show the clearly visible TO [ $\left.\mathrm{E}_{1}(\mathrm{TO})\right]$ phonon mode of the $\mathrm{InN}$ at $479 \mathrm{~cm}^{-1}$ just for film that were deposited at 50:50 N $\mathrm{N}_{2}$ : Ar. The X-ray diffraction results indicate that the layers consist of InN nanocrystals. The highest intensity of InN (101) peak and the best nanocrystalline InN films can be seen under the deposition condition with $\mathrm{N}_{2} / \mathrm{Ar}$ gas mixture of $50: 50$.

\section{Introduction}

Recent research popularity indicates that InN has a large potential for photonic and high-speed electronic applications. This includes fundamental properties such as the band gap, which is important to assess the suitability of InN for multifarious device applications. The energy of the band gap can be varied by mixing the nitrides to their ternary combinations. The InN band gap had originally been specified to be around $2 \mathrm{eV}$ [1], with some recent measurements suggesting alternatively a band gap of $0.7 \mathrm{eV}$ [2] and 1.4-1.5 eV [3] based on photoluminescence and absorption experiments. If the band gap of $\mathrm{InN}$ is almost $0.7 \mathrm{ev}$, a new inoffensive high-efficiency solar cell including most of solar spectrum can be produced using only InN and its alloys. However, $\mathrm{InN}$ has received little attention, because high-grade single crystal $\mathrm{InN}$ is difficult to grow due to its low dissociation temperature [4] and less suitable substrates [5].
Silicon $(\mathrm{Si})$ is a very interesting substrate material for the fabrication of InN-based devices because of the advantages in thermal and electrical conductivity as well as cost-efficient substrates and accessibility in large diameters. Recently, the growth of GaN on Si (110) substrates has been studied [6]. However, to the best of our knowledge, the growth of InN on Si (110) has not been explored. Si (110) is a surface orientation generally used in silicon technology, and the growth of InN on such substrates should be suitable for future III-N device integration.

InN films have been prepared by multiple methods such as metal organic chemical vapor deposition (MOCVD), molecular beam epitaxy (MBE), atomic layer epitaxy, radiofrequency (RF) sputtering, and direct current sputtering. MOCVD and MBE can be used to grow single crystalline InN, but they are so costly and the size of the grown epilayer is limited. Generally, RF sputtering can be used for fabricating noncrystalline or polycrystalline $\mathrm{InN}$. 


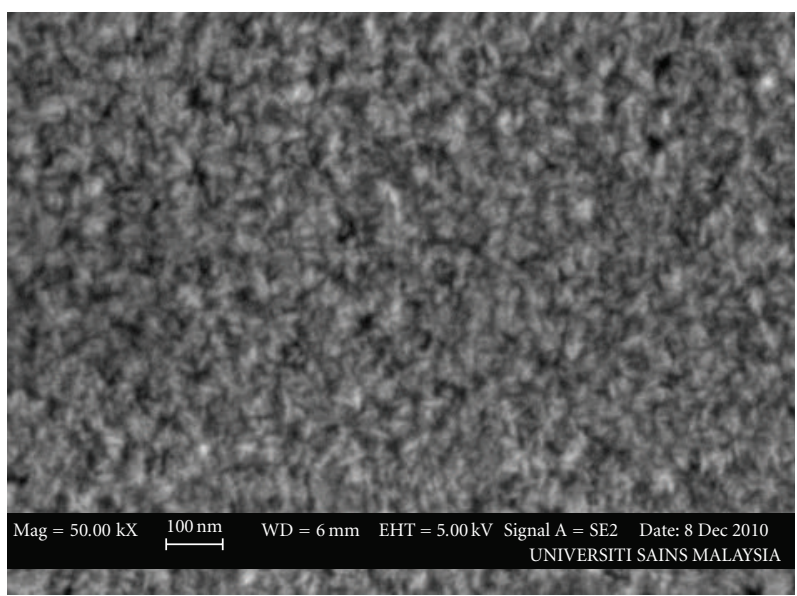

(a)

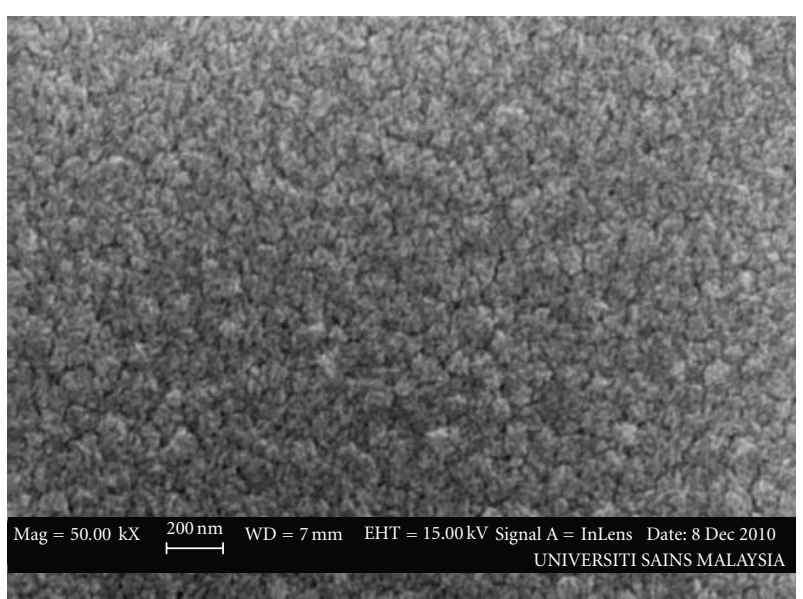

(b)

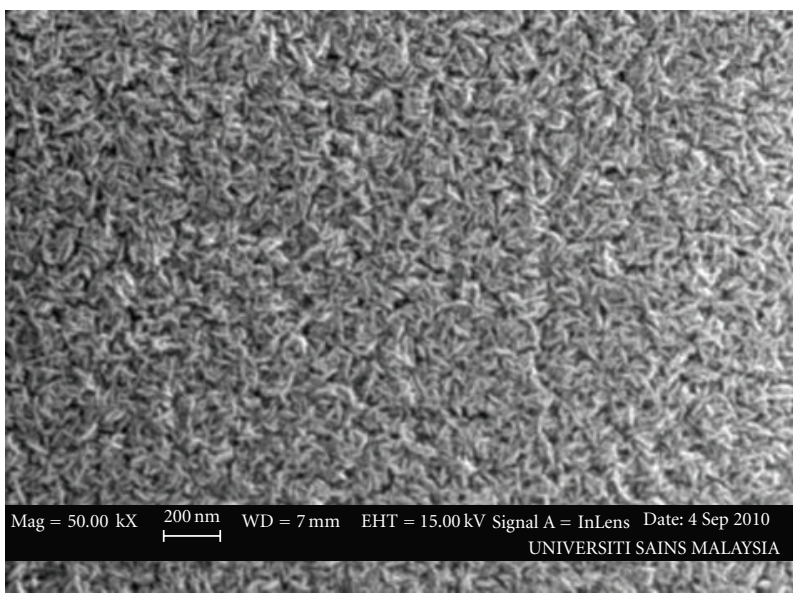

(c)

Figure 1: SEM images of InN grown on Si (110) while the deposition gas is (a) $100 \% \mathrm{~N}_{2}$, (b) $75 \% \mathrm{~N}_{2}-25 \% \mathrm{Ar}$, and (c) $50 \% \mathrm{~N}_{2}-50 \% \mathrm{Ar}$.
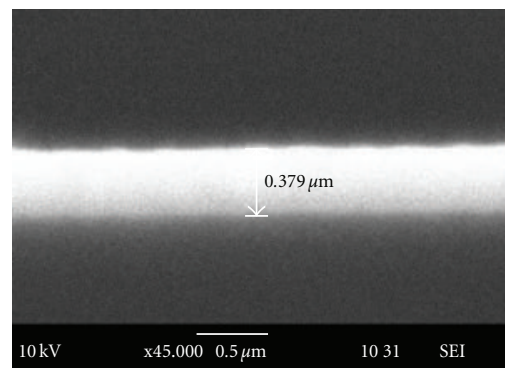

(a)
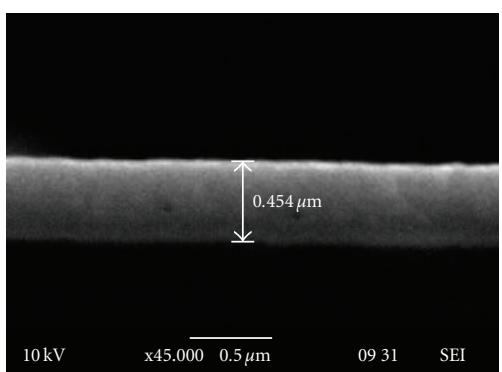

(b)

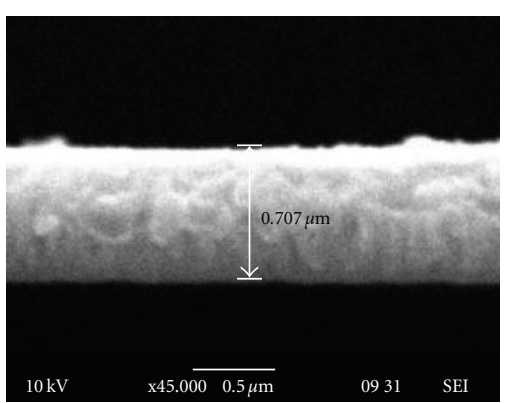

(c)

Figure 2: SEM cross-section view of InN grown on $\mathrm{Si}$ (110) while the deposition gas is (a) $100 \% \mathrm{~N}_{2}$, (b) $75 \% \mathrm{~N}_{2}-25 \%$ Ar, and (c) $50 \%$ $\mathrm{N}_{2}-50 \%$ Ar.

Up to now, there are few works devoted to studies of the InN thin films deposition by reactive sputtering. For example, Sullivan et al. investigated the optical properties and microstructure of reactive sputtered InN thin films with spectroscopic ellipsometry [7]. Guo et al. studied the effects of substrate temperature and also nitrogen: $\operatorname{argon}\left(\mathrm{N}_{2}\right.$ : $\left.\mathrm{Ar}\right)$ ratio on the composition and the structure of $\operatorname{InN}[8,9]$.
Inoue et al. fabricated the $\mathrm{InN}$ thin films in pure nitrogen $\left(\mathrm{N}_{2}\right)$ gas [10]. Despite these studies, the knowledge on the effects of deposition conditions on the InN films sputtered by pure $\mathrm{N}_{2}$ gas is still remain unclear. Nanocrystal solar cells are as cheap and easy to make as solar cells made from organic polymers and offer the added advantage of being stable in air, because they contain no organic materials. 


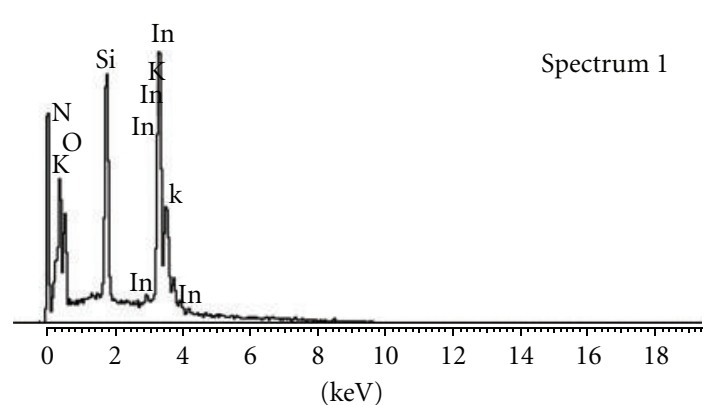

Full-scale 1064 cts cursor: -1074 keV (0 cts)

(a)

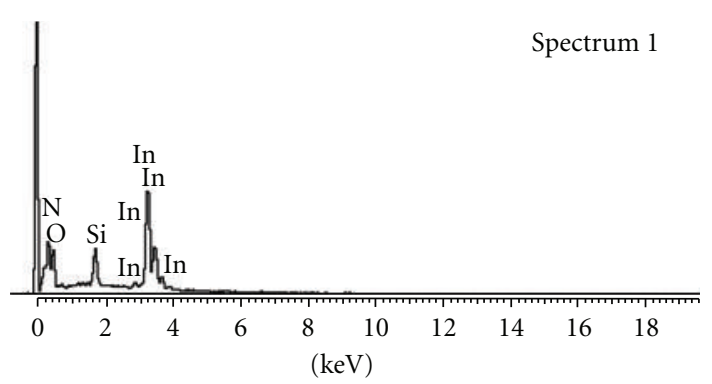

Full-scale 1031 cts cursor: $-0.831 \mathrm{keV}$ (0 cts)

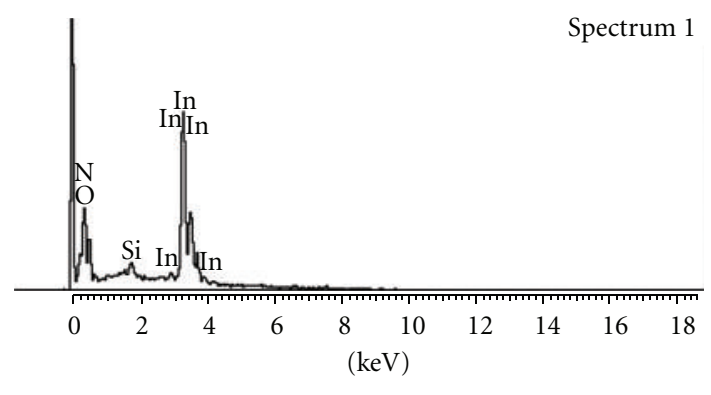

Full-scale 842 cts cursor: $-1.763 \mathrm{keV}$ (0 cts)

(c)

Figure 3: EDX of InN grown on $\mathrm{Si}$ (110) while the deposition gas is (a) $100 \% \mathrm{~N}_{2}$, (b) $75 \% \mathrm{~N}_{2}-25 \% \mathrm{Ar}$, and (c) $50 \% \mathrm{~N}_{2}-50 \%$ Ar.

In order to verify the characteristics listed above, a series of InN samples on Si (110), obtained with different $\mathrm{N}_{2}$ : $\mathrm{Ar}$ ratio, were fabricated and characterized in order to correlate the films properties with the $\mathrm{N}_{2}$ : Ar ratio.

\section{Experimental Details}

InN films were obtained at ambient temperature by reactive RF sputtering with a $13.56 \mathrm{MHz}$ RF power supply and a pure 3 inch diameter Indium target with purity of $99.999 \%$ in $\mathrm{Ar}$ and $\mathrm{N}_{2}$ atmosphere. The mixture of gaseous compositions was varied from high $\mathrm{N}_{2}$ to $50 \% \mathrm{~N}_{2}$ and Ar concentrations. The deposition pressure and the RF power was maintained constant at approximately $2.2 \times 10^{-2}$ Torr and $65 \mathrm{~W}$, respectively. The base vacuum pressure was around $2.5 \times 10^{-5}$ Torr and the target was cleaned with a $5 \mathrm{~min}$ presputter by Ar plasma.

The films were deposited onto $n$-type (110) single crystalline silicon substrates. To remove the surface contamination, the Si wafers were previously cleaned by the standard RCA method [11]. Sputtering gases ( $\mathrm{Ar}$ and $\mathrm{N}_{2}$ : 99.999\%) were introduced into the chamber for three different types of gas ratio $\left(\mathrm{N}_{2}: \mathrm{Ar}=100: 0,75: 25\right.$, and $\left.50: 50\right)$. The growth conditions are summarized in Table 1.

The obtained films were characterized with X-ray diffraction (XRD, PAN alytical X'pert PRO MRD PW3040), atomic force microscopy (AFM, ULTR Objective), scanning electron microscopy (SEM, FESEM LEO Supra 50VP) and energy dispersive X-ray spectroscopy (EDX) attached to SEM. The
TABLE 1: Sputtering condition for InN deposition.

\begin{tabular}{lc}
\hline Target & Indium $(99.999 \%)$ \\
\hline Target diameter & 3 in \\
Substrate & silicon $(110)$ \\
RF power & $60-70 \mathrm{~W}$ \\
Substrate temperature & Room temperature, $25^{\circ} \mathrm{C}$ \\
Target-substrate distance & $8 \mathrm{~cm}$ \\
Deposition time & 3 hours \\
Base pressure & $2.5 \times 10^{-5}$ Torr \\
Sputtering pressure & $2.2 \times 10^{-2}$ Torr \\
\hline
\end{tabular}

optical properties of InN layers were examined by Fourier transform infrared (FTIR, Perkin Elmer Spectrum GX) and micro-Raman spectroscopy (Jobin Yvon HR 800 UV) at room temperature.

\section{Results and Discussion}

The morphology and nanocrystalline structure of the InN thin films deposited on Si (110) were examined by using SEM. The results are shown in Figure 1. It can be seen that the films consists of agglomerated nanocrystals. The thickness of the InN films as obtained from the SEM image cross section are approximately $0.38,0.45$, and $0.70 \mu \mathrm{m}$ for the gas ratio of $100 \% \mathrm{~N}_{2}, 75 \% \mathrm{~N}_{2}$, and $50 \% \mathrm{~N}_{2}$, respectively, as shown in Figure 2. These results clearly indicate that by adding the Ar gas during the deposition, the thickness of 


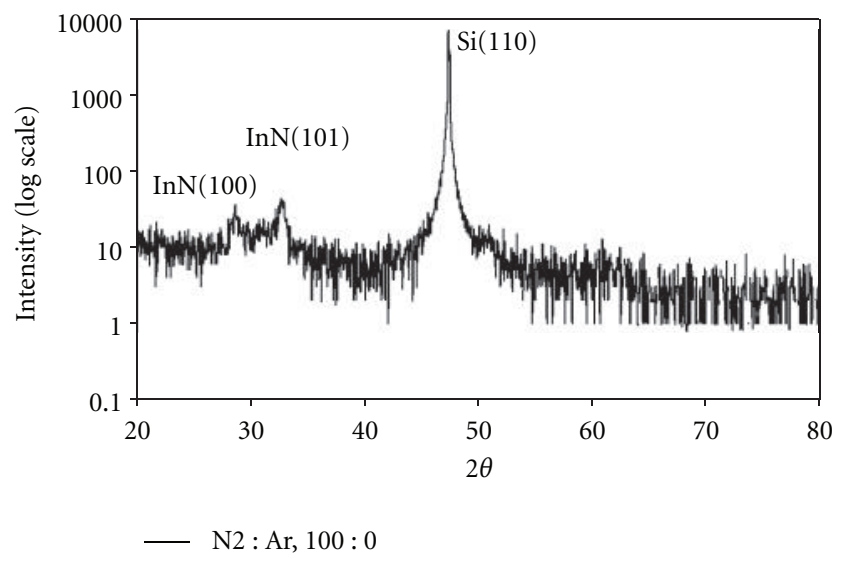

(a)

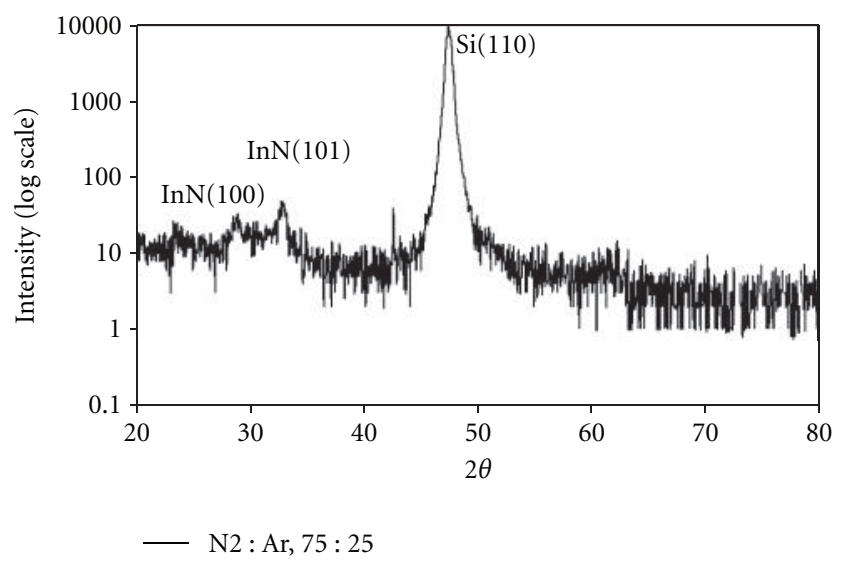

(b)

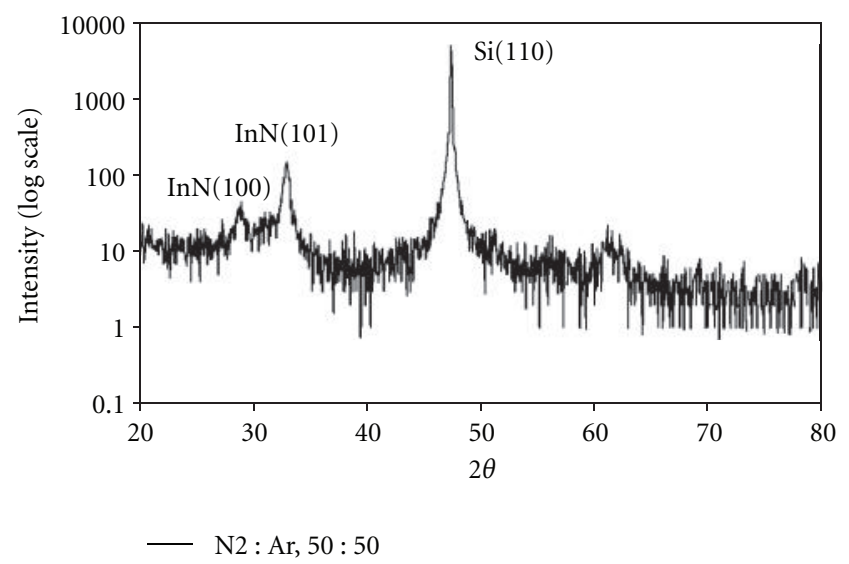

(c)

FIgURE 4: XRD spectrum of InN thin film on $\mathrm{Si}$ (110) substrates.

InN increase considerably. This fact may be determined from the fact that nitrogen has a higher electron capture ability and a lower sputtering yield than Argon, which decreases the density of plasmas. The higher density of plasma will bomb down more In particles from the target, which react with nitrogen to form more InN particles on the substrates and consequently increase the thickness of the layer [12]. Figure 3 shows the EDX spectra for the InN thin films grown on $\mathrm{Si}$ (110) substrates with different ratio of $\mathrm{N}_{2} / \mathrm{Ar}$. It can be seen that the films consist of In, large amount of $\mathrm{N}$, and very little $\mathrm{O}$. This result suggests that the film might possibly contain some $\mathrm{InN}, \mathrm{In}_{2} \mathrm{O}_{3}$ or, even $\mathrm{InN}_{x} \mathrm{O}_{y}$. However, the growth of $\mathrm{In}_{2} \mathrm{O}_{3}$ needs rigorous conditions such as high temperature and high pressure [13]. Therefore, it is difficult to obtain $\mathrm{In}_{2} \mathrm{O}_{3}$ by RF sputtering. The element of oxygen in all the films most probably arises from the $\mathrm{SiO}_{2}$. The $\mathrm{Si}$ surface is prevalently oxidized by dissolved oxygen during cleaning the substrates by RCA method. Note that the potassium element is most probably arisen from the contamination from the previous measurements.

The 20/ $\omega$ X-ray diffraction patterns of the InN thin films grown on $\mathrm{Si}$ (110) substrates at room temperature in the three types of sputtering gases are given in Figure 4. The results reveal that the three InN films grown in different gases ratio have a qualitatively similar crystalline structure. The same InN (101) and InN (100) peaks was observed in XRD $2 \theta$ spectra for the three samples, while slightly higher peak intensity was observed when the sample was deposited with $\mathrm{N}_{2}$ :Ar, 50:50. This means that the gas ratio directly affects the crystalline quality of InN nanostructure and with increase of the Ar gas, the intensities of the InN (101) and InN (100) diffraction peaks increased. The activation energy on the substrate surface may be declined with increasing $\mathrm{N}_{2}$ concentration, because various high-energy metal particles reach the substrate surface [9]. As a result, the crystallinity of the film degraded. A similar trend is also observed in the cases of AlN [14, 15] and GaN [16], where the crystallity degraded when the $\mathrm{N}_{2}$ content in the sputtering gas exceeds the critical values.

In order to obtain the detailed structure information, we calculated the crystal size of InN nanocrystals based on the XRD results, that is, by using the Scherrer formula [17]

$$
t=\frac{0.89 \lambda}{B \cos \theta_{B}},
$$

where $\lambda$ is wavelength (in Angstrom), $B$ is the (full-width at half maximum $(\mathrm{FWHM})) \times \pi / 180, \theta_{B}$ is diffraction peak angle. 


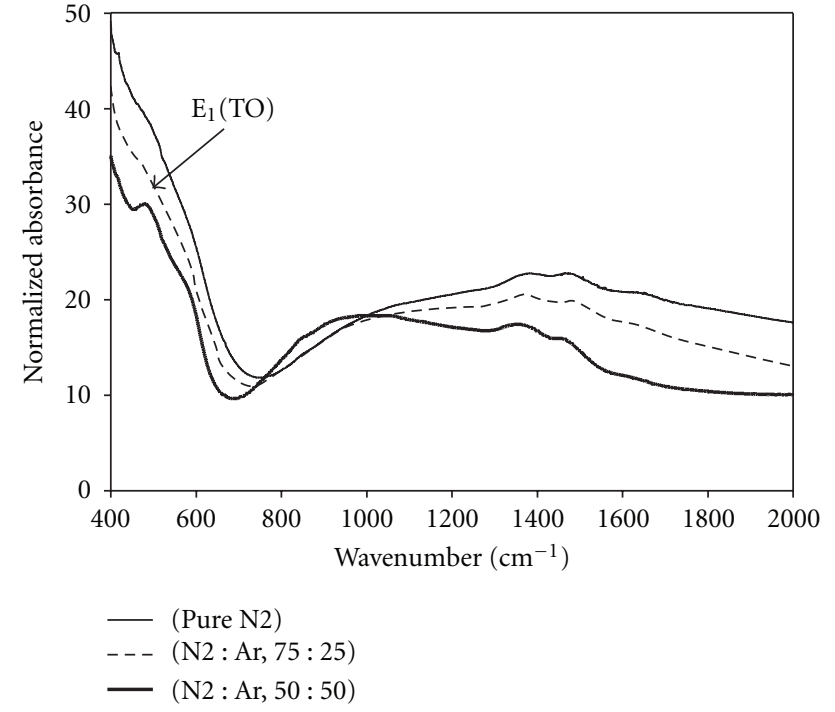

FIGURE 5: InN FTIR spectra on Si (110).

TABLe 2: Full-width at half maximum (FWHM) of InN (101) diffraction peak and Crystal size of InN with different percentage of $\mathrm{Ar}$ gas ratio during deposition.

\begin{tabular}{lccc}
\hline $\mathrm{N}_{2}:$ Ar gas ratio & $100: 0$ & $75: 25$ & $50: 50$ \\
\hline FWHM & 0.516 & 0.492 & 0.197 \\
Crystal size $(\mathrm{nm})$ & 15.87 & 16.65 & 41.64 \\
\hline
\end{tabular}

Table 2 shows the dependence of FWHM of InN (101) diffraction peak and the crystal size of $\mathrm{InN}$ on the $\mathrm{N}_{2} / \mathrm{Ar}$ concentrations during deposition. Again, it is perceived that the higher Ar flow leads to enhanced structural order for $\mathrm{Si}$ (110) substrates, as displayed by the smaller FWHM attained for this case. It is well known that FWHM of the peak of XRD in $2 \theta$-mode is affected by the grain size and the distribution of lattice constant due to the lattice distortion [8]. The FWHM of InN (101) peak decreases with the increasing of Ar gas, while the crystal size of InN nanocrystals increased.

From Table 2, it is also can be seen that the crystal sizes of the InN films are less than $50 \mathrm{~nm}$. At $\mathrm{N}_{2}$ : Ar ratio of $50: 50$ where the strongest reflection from $C$-plane is observed, the crystal size reaches its maximum due to its smallest FWHM, and it is indicated that InN films which grew at $\mathrm{N}_{2}$ : Ar ratio of $50: 50$ has the best nanocrystallite. The reason is mainly due to the higher ratio of $\mathrm{N}_{2}$ : Ar will tend to create higher plasma density. Consequently, more In particles can react with $\mathrm{N}_{2}$.

To obtain further information about structure and bond formation, FTIR measurements were performed for the same InN films previously analyzed by XRD. The FTIR spectra of InN thin films grown on the $\mathrm{Si}(110)$ substrates are shown in Figure 5. For InN films, the feature corresponding to the $\mathrm{E}_{1}$ (TO) phonon modes of the $\mathrm{InN}$ are clearly observed at $479 \mathrm{~cm}^{-1}$ for the deposition condition of $\mathrm{N}_{2} /$ Ar gas mixture of 50:50, which is comparable to the reported values for wurtzite InN [18]. However, we did not observe similar peak in other gas ratio compositions. This is mainly due to the

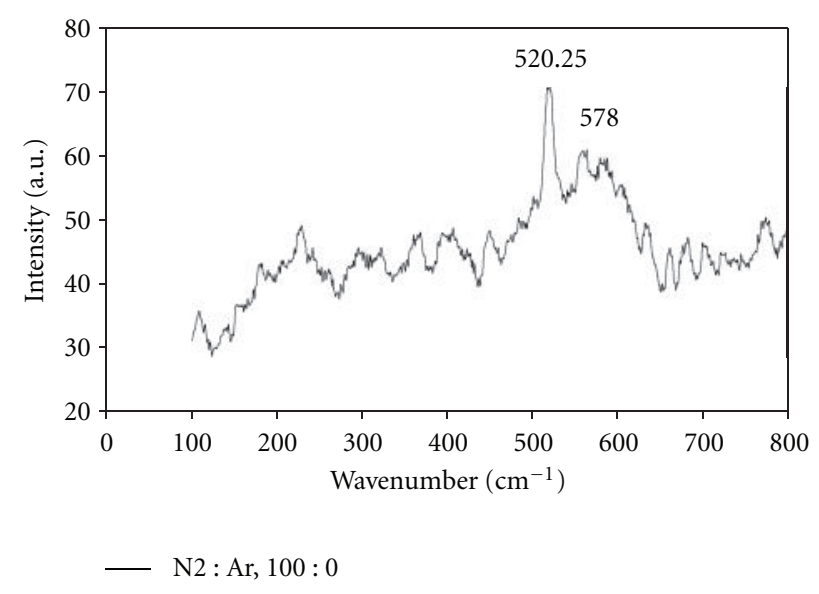

(a)

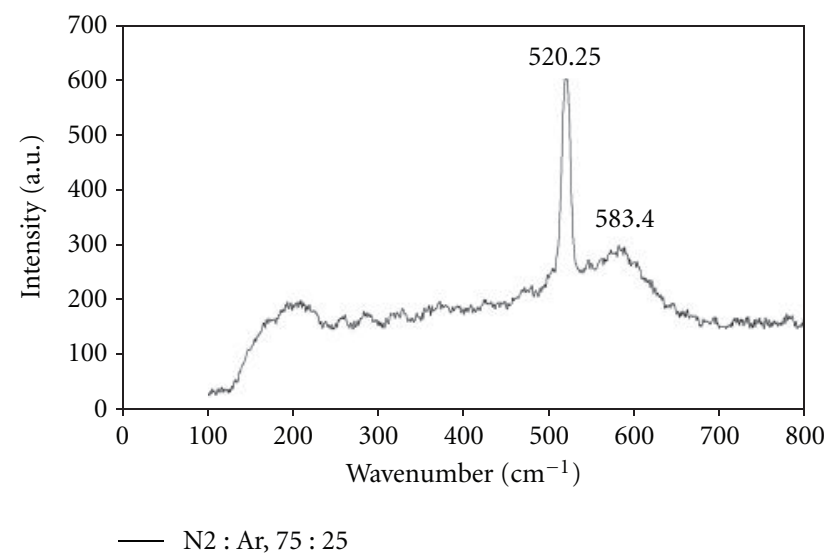

(b)

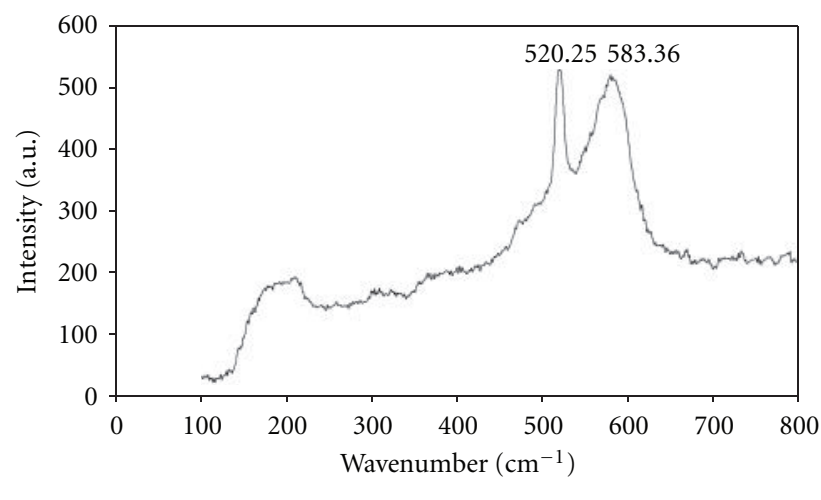

- N2: Ar, $50: 50$

(c)

Figure 6: (a, b, and c) Room temperature micro-Raman spectrum of InN/Si (110) substrates in different gas ratios.

weak crystalline structure. These results are consistent with the $\mathrm{XRD}$ results as discussed previously.

Micro-Raman measurements were carried out at room temperature in backscattering geometry using an Ar-ion laser. Figure 6 illustrates Raman spectra for the grown $\mathrm{InN}$ film in the spectral range from 100 to $800 \mathrm{~cm}^{-1}$. The Si substrate peak is visible at $520 \mathrm{~cm}^{-1}$. For InN thin films, 
Topography (forward 3D of InN_110_3

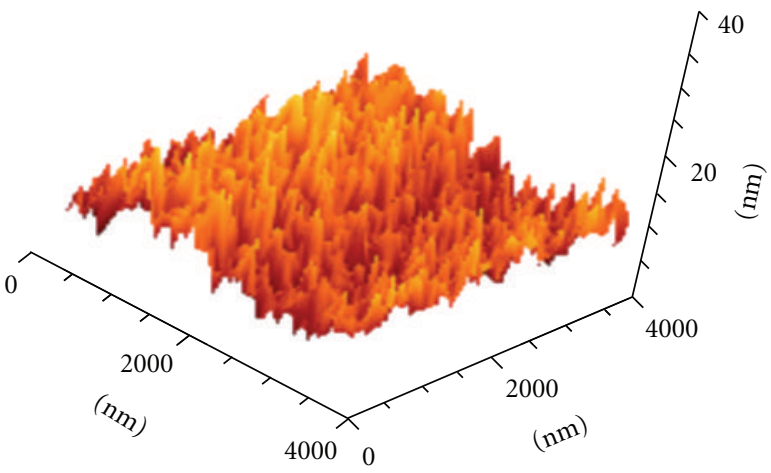

(a)

Topography (forward) 3D of InN_110_3

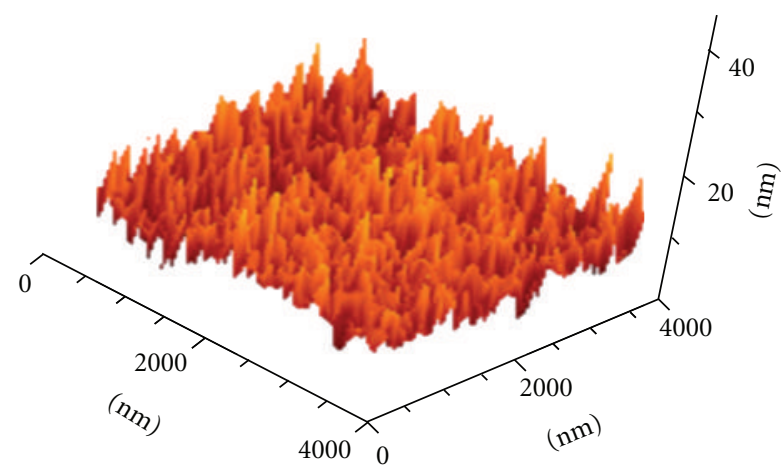

(b)

Topography (forward) 3D of InN_110_2

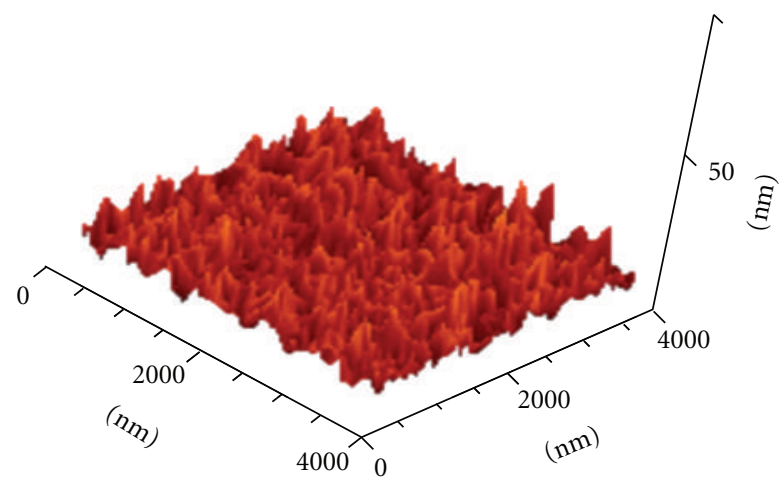

(c)

FIgURE 7: AFM images of the InN film deposited on $\mathrm{Si}$ (110) while the deposition gas is (a) $100 \% \mathrm{~N}_{2}$, (b) $75 \% \mathrm{~N}_{2}-25 \% \mathrm{Ar}$, and (c) $50 \%$ $\mathrm{N}_{2}-50 \%$ Ar. only the allowed phonon mode of $\mathrm{A}_{1}(\mathrm{LO})$ is visible at $578 \mathrm{~cm}^{-1}, 583.4 \mathrm{~cm}^{-1}$, and $583.36 \mathrm{~cm}^{-1}$, for films grown at three different types of $\mathrm{N}_{2}$ : Ar gas ratio: $100: 0,75: 25$, and $50: 50$, respectively. It is clear that the strongest $A_{1}(L O)$ is for InN which is grown in a 50:50, $\mathrm{N}_{2}$ : Ar gas ratio.

The zincblende structure (spatial group $T_{\mathrm{d}}^{2}-\mathrm{F} 43 \mathrm{~m}$ ) has only two Raman-active phonons $\mathrm{F}_{2}(\mathrm{TO})$ and $\mathrm{F}_{2}(\mathrm{LO})$. The wurtzite structure (spatial group $\mathrm{C}_{6 \mathrm{v}}^{4}-\mathrm{P} 6_{3} \mathrm{mc}$ ), which is the most stable, has six Raman-active phonons, $\mathrm{A}_{1}(\mathrm{TO}), \mathrm{A}_{1}(\mathrm{LO})$, $\mathrm{E}_{1}(\mathrm{TO}), \mathrm{E}_{1}(\mathrm{LO})$, and $2 \mathrm{E}_{2}[19]$. Therefore, the $\mathrm{A}_{1}(\mathrm{LO})$ peak which observed in the spectra indicates that the wurtzite phase must be present. Scattering intensities and phonon frequencies, determined by means of Raman spectroscopy, are sensitive to composition, presence of disorder, impurities, and the crystal quality of the structure under investigation [20]. The structural analyses of Raman spectra and comparison with the results obtained from XRD measurements allow us to conclude that InN films which grew at N2: Ar ratio of $50: 50$ has the best crystalline quality.

To characterize the surface morphology of InN films grown on Si substrate, we measured the surface roughness using AFM. Figure 7 shows the AFM images of the InN films. The films contain small grains. The surface is flat in nano scale and the root mean square (RMS) surface roughness measured by AFM are about 2.78, 2.97, and $3.32 \mathrm{~nm}$ over a $4000 \times 4000 \mathrm{~nm}^{2}$ scan area, respectively, for $100 \%, 75 \%$, and $50 \%$ of $\mathrm{N}_{2}$ gases. The AFM measurements agreed with SEM images, because small grain size induces a smooth surface [21].

\section{Conclusion}

Nanocrystalline InN films on Si (110) have been successfully grown by $\mathrm{RF}$ reactive magnetron sputtering in different $\mathrm{N}_{2}$ : Ar gas ratio in ambient temperature. The structure of films was characterized by XRD, SEM, EDX, AFM, FTIR, and Raman spectroscopy. Both XRD and Raman scattering revealed that the film contains hexagonal InN. The crystalline size of the InN films calculated by the Scherrer equation are about $15.87 \mathrm{~nm}, 16.65 \mathrm{~nm}$, and $41.63 \mathrm{~nm}$ for $100: 0$, $75: 25$, and $50: 50 \mathrm{~N}_{2}:$ Ar proportion, respectively. The best nanocrystalline InN films with highly $c$-axis preferred orientation were attained when the deposition gas ratio of $\mathrm{N}_{2}$ : Ar was $50: 50$.

\section{Acknowledgments}

Financial support from RU Grant (no. 1001/PFIZIK/814090) and University Sains Malaysia are gratefully acknowledged. The authors thank Mr. Ooi Poh Kok for FTIR measurements.

\section{References}

[1] T. L. Tansley and C. P. Foley, "Optical band gap of indium nitride," Journal of Applied Physics, vol. 59, no. 9, pp. 32413244, 1986.

[2] J. Wu, W. Walukiewicz, K. M. Yu et al., "Small band gap bowing in $\mathrm{In}_{1-x} \mathrm{Ga}_{x} \mathrm{~N}$ alloys," Applied Physics Letters, vol. 80, no. 25, pp. 4741-4743, 2002. 
[3] T. V. Shubina, S. V. Ivanov, V. N. Jmerik et al., "Mie Resonances, Infrared Emission, and the Band Gap of InN," Physical Review Letters, vol. 92, no. 11, pp. 117407-1-117407-4, 2004.

[4] O. Takai, K. Ikuta, and Y. Inoue, "Growth and nanostructure of InN thin films deposited by reactive magnetron sputtering," Thin Solid Films, vol. 318, no. 1-2, pp. 148-150, 1998.

[5] T. Yamaguchi, K. Mizuo, Y. Saito, T. Noguchi, T. Araki, and Y. Nanishi, "Single crystalline InN films grown on Si substrates by using a brief substrate nitridation process materials," Materials Research Society Symposium Proceedings, vol. 743, pp. L3.26.1-L3.26.6, 2003.

[6] F. Ruiz-Zepeda, O. Contreras, A. Dadgar, and A. Krost, "Microstructure of gallium nitride films grown on silicon (110)," Applied Physics Letters, vol. 96, no. 23, Article ID 231908, 2010.

[7] Motlan, E. M. Goldys, and T. L. Tansley, "Optical and electrical properties of InN grown by radio-frequency reactive sputtering," Journal of Crystal Growth, vol. 241, no. 1-2, pp. 165-170, 2002.

[8] Q. Guo, N. Shingai, M. Nishio, and H. Ogawa, "Deposition of InN thin films by radio frequency magnetron sputtering," Journal of Crystal Growth, vol. 189-190, pp. 466-470, 1998.

[9] Q. Guo, N. Shingai, Y. Mitsuishi, M. Nishio, and H. Ogawa, "Effects of nitrogen/argon ratio on composition and structure of InN films prepared by r.f. magnetron sputtering," Thin Solid Films, vol. 343-344, no. 1-2, pp. 524-527, 1999.

[10] S. Inoue, T. Namazu, T. Suda, and K. Koterazawa, "InN films deposited by rf reactive sputtering in pure nitrogen gas," Vacuum, vol. 74, no. 3-4, pp. 443-448, 2004.

[11] W. Kern and D. Puotinen, "Cleaning solutions based on hydrogen peroxide for use in silicon semiconductor technology," RCA Review, vol. 31, pp. 187-206, 1970.

[12] J. Li, S. Wu, and J. Kang, "ZnO films deposited by RF magnetron sputtering," in Proceedings of the 13th IEEE Semiconducting and Semi-Insulating Materials Conference (SIMC '04), pp. 77-80, September 2004.

[13] D. Yu, S. H. Yu, S. Zhang, J. Zuo, D. Wang, and Y. Qian, "Metastable hexagonal $\operatorname{In}_{2} \mathrm{O}_{3}$ nanofibers templated from InOOH nanofibers under ambient pressure," Advanced Functional Materials, vol. 13, no. 6, pp. 497-501, 2003.

[14] H. Okano, Y. Takahashi, T. Tanaka, K. Shibata, and S. Nakano, "Preparation of c-axis oriented AIN thin films by lowtemperature reactive sputtering," Japanese Journal of Applied Physics, Part 1, vol. 31, no. 10, pp. 3446-3451, 1992.

[15] M. V. Pelegrini and I. Pereyra, "Characterization of AlN films deposited by r.f. reactive sputtering aiming MEMS applications," Physica Status Solidi (C), vol. 7, no. 3-4, pp. 840-843, 2010.

[16] S. Strite and H. Morkoc, "GaN, AIN, and InN: a review," Journal of Vacuum Science \& Technology B, vol. 10, no. 4, pp. 1237-1267, 1992.

[17] D. Y. Lee, I. S. Kim, and J. S. Song, "Effect of heat treatment on structural characteristics and electric resistance in $\mathrm{TaNx}$ thin film deposited by RF sputtering," Japanese Journal of Applied Physics, Part 1, vol. 41, no. 7, pp. 4659-4662, 2002.

[18] P. M. Fauchet, L. Tsybeskov, C. Peng et al., "Light-emitting porous silicon: materials science, properties, and device applications," IEEE Journal on Selected Topics in Quantum Electronics, vol. 1, no. 4, pp. 1126-1139, 1995.

[19] F. Agulló-Ruedaa, E. E. Mendezb, B. Bojarczukc, and S. Guhac, "Raman spectroscopy of wurtzite InN films grown on Si," Solid State Communications, vol. 115, pp. 19-21, 2000.
[20] M. Kitajima, "Defects in crystals studied by Raman scattering," Critical Reviews in Solid State and Materials Sciences, vol. 22, no. 4, pp. 275-349, 1997.

[21] K. S. Kim and H. W. Kim, "Structural characterization of $\mathrm{ZnO}$ thin film grown on Si-based substrates by metal organic chemical vapour deposition," Journal of Korean Physical Society, vol. 42, pp. 149-153, 2003. 

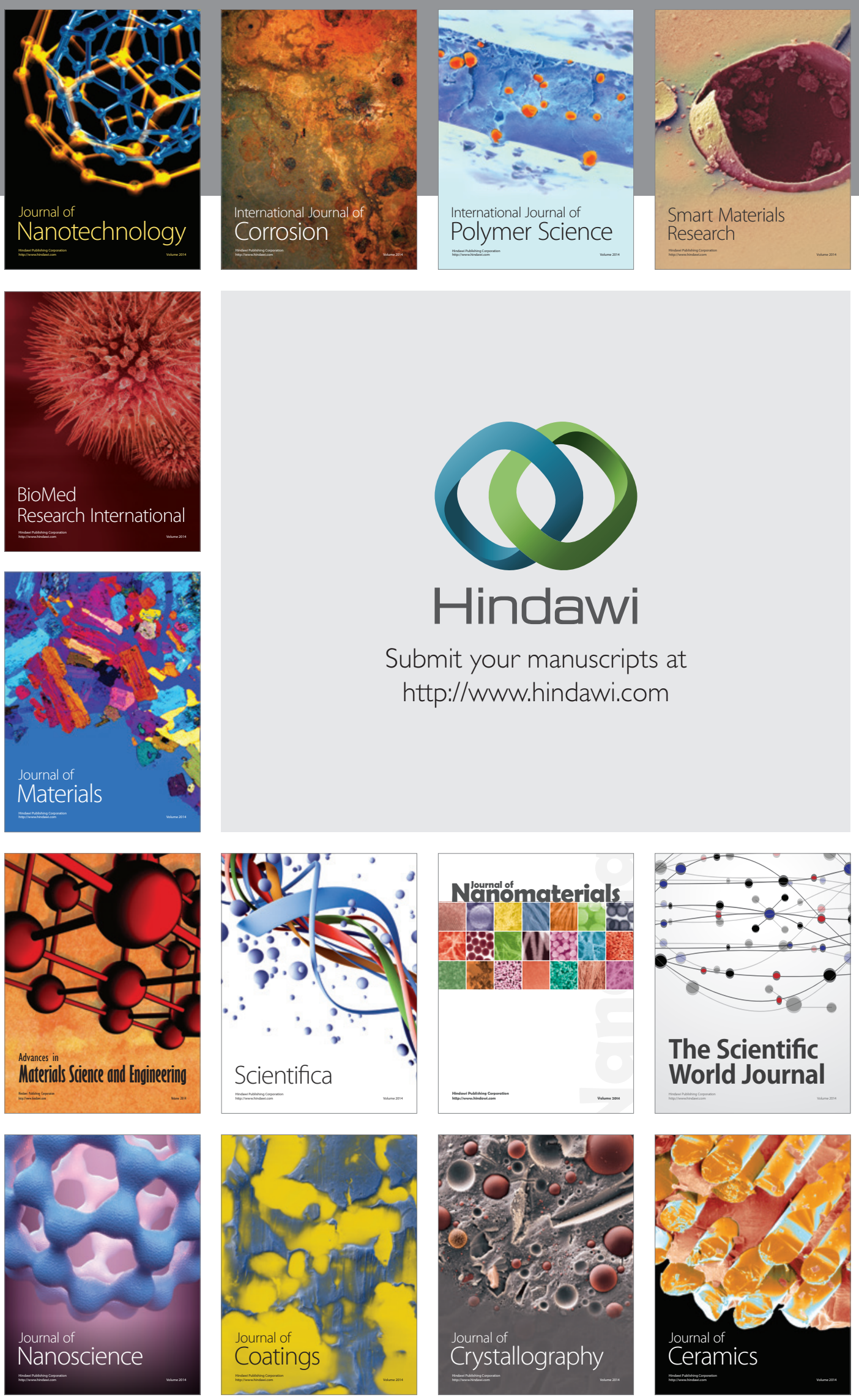

The Scientific World Journal

Submit your manuscripts at

http://www.hindawi.com

\section{World Journal}

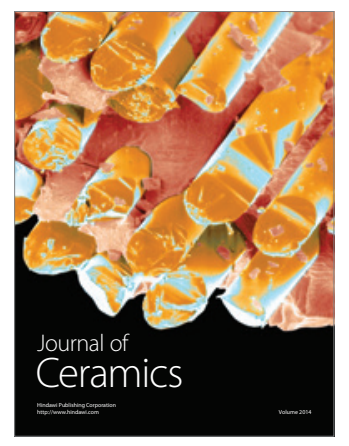

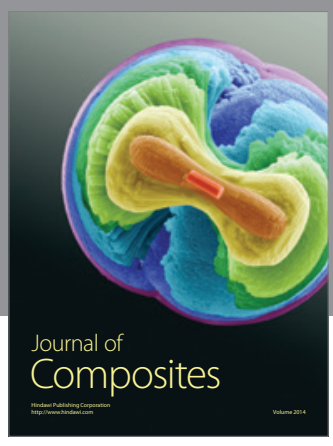
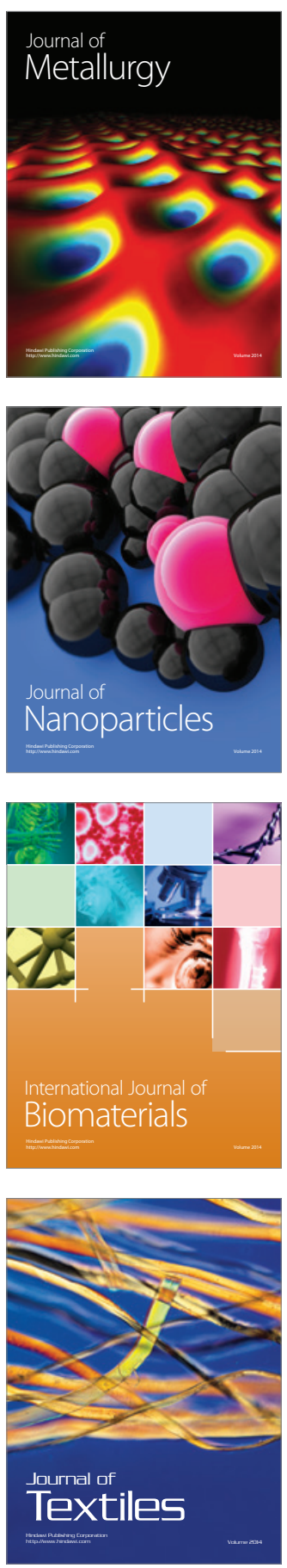